\title{
Physiological and kinanthropometrical parameters of an elite climber. Single case study
}

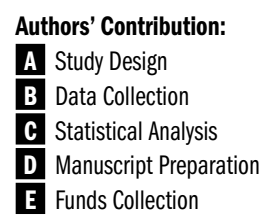

\author{
Gaizka Mejuto $^{1 \mathrm{ABCD}}$, Julio Calleja-González ${ }^{1,2 \mathrm{ABCD}}$, Jose Antonio Lekue ${ }^{2 \mathrm{~B}}$, Xabier Leibar $^{2 \mathrm{~B}}$, \\ Ramón Gárate $^{3 \mathrm{~B}}$, Jose Ignacio Emparanza ${ }^{4 \mathrm{AD}}$, Julen Erauzkin ${ }^{2 \mathrm{~B}}$, Maialen Beldarrain ${ }^{2 \mathrm{~B}}$, \\ Nicolás Terrados ${ }^{5,6 \mathrm{ACD}}$ \\ ${ }^{1}$ Laboratory of Analysis of Sport Performance, Sport and Physical Education Department, Faculty of Sport Sciences, University \\ of the Basque Country, Spain \\ ${ }^{2}$ Sport Performance Center, Culture Department, Basque Government, Spain \\ ${ }^{3}$ Traumatology Department, Gipuzkoa Policlinic, Spain \\ ${ }^{4}$ Clinical Epidemiology Unit, CASPE, CIBERESP, Donostia University Hospital, Spain \\ ${ }^{5}$ Regional Unit of Sport Medicine- Avilés City-Council Foundation, Spain \\ ${ }^{6}$ Functional Biology Department, University of Oviedo, Spain
}

Source of support: Departmental sources

Received: 29 November 2011; Accepted: 27 August 2012; Published online: 10 September 2012

Background and Study Aim:

Material/Methods:

Results:

Conclusions:

Key words:

Author's address:

\footnotetext{
Extreme altitude - altitudes above $5500 \mathrm{~m}$ above sea level.

HP - hypoxia
}

\section{Abstract}

Extreme altitude climbing effects have been described in several studies. Usually these studies are carried out on expeditions but not longitudinally. The aim of this study is to describe physiological and kinanthropometrical changes over the time in a top-level climber.

This is a single-subject study on an individual career part (from ages 27 to 41). Some physiological and kinanthropometrical parameters were analysed in 3 different season parts at sea level; before (PRE), after (POST) and off climbing expeditions (OFF). All expeditions were $>7000 \mathrm{~m}$.

No changes were found in physiological parameters during the period of study regarding to season part. Kinanthropometry in contrast, presented significant changes $(\mathrm{P}<0.01)$ in two skinfolds (PRE/OFF vs. POST), whereas $\sum$ of SF showed differences between (PRE vs. OFF). Results also indicate some significant correlations $(\mathrm{P}<0.05)$ between both kinanthropometrical and physiological variables and the participant aging process.

The high fitness level of the participant combined with his gift for acclimatization and a broad climbing career, maintain physiological and kinanthropometrical stability during the analysed period even after repeated exposure to extreme altitudes. However, aging process appears to be involved in maximal exercise cardiovascular capacity decline. Surprisingly, kinanthropometrical variables such as weight, BMI and fat percentage showed lower values through the time attributable probably to a high physical activity.

extreme altitude $\bullet$ climbing $\bullet$ physiology $\bullet$ kinanthropometry

Gaizka Mejuto, Laboratory of Analysis of Sport Performance. Sport and Physical Education Department. Faculty of Sport Sciences. University of the Basque Country. Portal de Lasarte, 71. Vitoria-Gasteiz 01007 (Álava), Spain; e-mail: gaizka.mejuto@ehu.es

\section{BACKGROUND}

Extreme altitude begins at $5500 \mathrm{~m}$ above sea level [1] but summiting the highest peaks of the world in Himalaya, involves exposures over $8000 \mathrm{~m}$. These mountains, are in the threshold of human limits of tolerance to hypoxia (HP) [2]. Studies of individuals who face these challenges usually report physiological alterations as human body responses to HP. At an altitude of $8500 \mathrm{~m}$, often called "Death Zone", the barometric pressure is $70 \%$ less than at sea level, and sometimes records values of $80 \%$, like on the summit of the 
O2 - oxygen.

HR - physiol. Subject's heart rate. Determined by the number of heart beats per unit of time. In many type of exercise, the increase in heart rate is linear with the increase in rate of exercise.

Expressed in beats per minute [77].

MHR - physiol. Subject's heart rate at maximum workload. Expressed in beats per minute. Indicator that $\mathrm{VO}_{2 \max }$ has been reached. Highly conditioned endurance athletes tend to have lower MHR values than untrained individuals of the same age [79].

[LA]-physiol. Blood lactate concentration is commonly used to predict anaerobic glycolytic ability. Expressed in mmol per litre of blood.

M[LA] - maximum blood lactate concentration expressed in mmol per litre of blood. An accumulation of blood lactate is

correlated with an increase in pulmonary ventilation beyond the demand of a sufficient oxygen supply to exercising muscles [77].

$\mathrm{VO}_{2}$ - maximal oxygen uptake. A common measure of fitness for endurance activities. The maximum

volume of oxygen the body can consume per time unit [82]. In our case expressed as millilitre per $\mathrm{kg}$ of body weight per minute $\left(\mathrm{mL}^{-1} \mathrm{~kg}^{-1} \mathrm{~min}^{-1}\right)$
Everest mountain, where the values of barometric pressure oscillate between 251 to 253 Torr (when is used to be climbed). In these altitudes, the inspired $\mathbf{O}_{2}$ pressure is 43 Torr, close to the limit tolerated by the human body [3]. Different hazards threat mountaineers when they attempt to reach these mountains. Chronic HP above 6000-7000 m, can cause a sea level resident to became more vulnerable to different altitude related pathologies. Commonly observed problems range from mild headache to potentially lethal edemas $[4,5]$. This chronic HP combined with extremely low temperatures and dehydration, among other risks at extreme altitude, make the environment life threatening [6].

Heart Rate (HR). Physiological parameters are susceptible to changes in extreme altitudes. At cardiorespiratory level, the HR, is affected under HP situations immediately upon arrival even at moderate altitudes above $1500 \mathrm{~m}$. This acute exposure to high altitude produces hypoxia-associated stimulation of the sympathetic nervous system. This response is further enhanced by physical activity and induces an increase in heart rate and blood pressure [7]. The persistent rise in HR at rest and during exercise at altitude, would appear to be mediated via sustained changes in autonomic nervous system activity and circulating catecholamine levels [8]. Hypoventilation induces a higher HR both at rest and in exercise, consistently higher in acute HP [9]. At high altitude, HR increases to $136 \%$ of the sea level value, but gradually decreases [10], giving a progressive decrement in its peak under conditions of acute HP (6 weeks after acclimatization to $5400 \mathrm{~m}$ ) [11]. Other field studies carried out by the "Silver Hut Expedition" certified previously exposed data [12]. In barometric pressure below $530 \mathrm{mmHg}$ ( $130 \mathrm{~m}$ of altitude gained above $3100 \mathrm{~m}$ ) the maximal HR (MHR) begins to descend in accordance with 1 beat $\cdot \mathrm{min}^{-1}$ for every $7 \mathrm{mmHg}$ [11].

Blood lactate accumulation [LA]. At extreme altitude, this parameter has shown in a low concentration in acclimatized subjects, even at maximal intensity exercises [13], arising the "lactate paradox" theory, which still remains as debate object [14-19]. After maximal exercise at altitudes exceeding $7500 \mathrm{~m}$, no increase of [MLA] at all despite the extreme $\mathrm{O}_{2}$ deprivation has been reported. It is predicted that above this altitude, there is no rise in [LA] during exercise. Sutton et al. (1988) [13] demonstrated the low maximal [LA] (M[LA]) in extreme altitude, showing that at altitudes over $7500 \mathrm{~m}$ above sea level [LA] did not surpass the $4 \mathrm{mmol} / \mathrm{L}$ in blood. The paradoxically low values are possibly related to plasma bicarbonate depletion [6]. Nevertheless, Brooks et al. (1998) [20], suggest that usually 2 fundamental questions are not considered to support this theory: 1) the cause of fatigue in extreme altitude, which cannot be due to low [LA] (blood and muscles) and 2) the paradoxically low cardiac outputs that occur even though myocardial function is highly preserved during maximal exercise in extreme HP [21]. Thus, progressively lower levels of skeletal muscle recruitment prevent the development of sufficient muscle power, leading to the termination of maximal exercise at progressively lower work rates, cardiac outputs, blood and muscle [LA] with increasing altitude. This control would protect the brain from dangerous levels of HP at extreme altitude [21]. $[\mathrm{LA}]$ is determined by factors in addition to hypoxemia such as circulating epinephrine, and net lactate release from active muscle beds rejecting beta-adrenergic influences. Savard et al. (1995) demonstrated that lower blood [LA] levels at altitude, is a function of muscle mass involvement rather than adrenergic activation, as normal peak values were reached during exercise with a small muscle mass [22]. In any case, M[LA] and [LA] at rest (R[LA]) at extreme altitude are still discussed among altitude physiologists and physicians [14-19].

Maximal oxygen consumption $\left(\mathrm{VO}_{2 \max }\right)$. At the altitude of Mt Everest, is reduced to 20-25\% of its sea level value, and it is exquisitely sensitive to barometric pressure especially above altitudes of $1500 \mathrm{~m}$. Seasonal variations of barometric pressure affect the ability of man to reach the summit without supplementary $\mathrm{O}_{2}$ [6]. For elite climbers, it was established in the research work of Pak et al. (2011) that the forecasting of a successful ascension, could be improved if the potential $\mathrm{VO}_{2 \max }$ was added to the standard definition parameters of aerobic metabolism, such as the $\mathrm{VO}_{2 \max }$ and anaerobic threshold of $\mathrm{O}_{2}$ uptake [23]. The potential $\mathrm{VO}_{2 \max }$ is considered to be the parameter of reserve growing in condition of realization of adaptive reaction to HP [23]. Also Cerretelli et al. [24] concluded that still at an altitude of $2500 \mathrm{~m}$, the $\mathrm{VO}_{2 \max }$ begins to fall between $5 \%$ and $10 \%$ comparing with sea level values. Other research works reporting changes after chronic acute HP, like published by Robach et al. [25], simulate the ascent of 8 men to Everest with an hypobaric chamber (COMEX). In this study, the $\mathrm{VO}_{2 \max }$ decreased $59 \%$ at $7000 \mathrm{~m}$ above sea level. On the other hand Takahashi et al. showed that elite climbers are characterized by their enhanced ventilatory response to HP rather than prominence in aerobic work capacity [26]. And when subjects return to sea level they did not appear to improve as Sutton et al. reported after Everest Operation II [13]. However, exposure to acute HP, makes this parameter to remain stable or even decrease mainly due to 3 reasons; 1 ) the reduction of pressure of inspired $\mathrm{O}_{2}, 2$ ) the impairment of pulmonary gas exchange, each explaining about onehalf of the drop in arterial $\mathrm{O}_{2}$ content, and 3) the reduction of maximal carbon monoxide explaining the remaining one-third of the loss in $\mathrm{VO}_{2}$ 
Kinanthropometry. Majority of the studies state that the practice of the extreme altitude mountaineering causes weight $(\mathbf{W})$ loss $[27,28]$. These authors concluded that the mechanisms could not be totally due to a misalignment between the food intakes and energy expenditure, but to a bad absorption of carbohydrates (CHO). On the other hand, the loss of water could play a determinant role. In this sense, it is necessary to consider the acute $\mathrm{HP}$ at the time of intestinal absorption of fats and CHO $[29,30]$. In this case, xylose plays a major role in a decrement of arterial $\mathrm{O}_{2}$ saturation impairing the correct absorption of CHO [31]. In 1981, the American Medical Research Expedition to Everest (AMREE) carried out an exhaustive control of these parameters. It was observed that the $70 \%$ of the total body fat lost during the expedition was while approaching at moderate altitude, against the $27.2 \%$, which was lost above $5,400 \mathrm{~m}$. It is also significant that the fat absorption decreased $48.5 \%$ in 3 subjects, and in 6 out of 7 members the excretion of xylose decreased until $24.3 \%$ at $6300 \mathrm{~m}$ of altitude. For this reason it can be deduced, that a high $\mathbf{F} \%$ does not protect from losses of muscular tissue [32]. On the other hand, Kayser et al. [33] used cutaneous skinfolds (SF) measurements before and after expedition to calculate the loss of fat and concluded that the loss is an average of $9 \%$ on the basis of the measurements made at $5000 \mathrm{~m}$ of altitude. In contrast, Kayser et al. [34] indicated that the food palatability could play an important role. At $5050 \mathrm{~m}$ of altitude, loss of body mass from fat and muscle tissue, and hence impairment of maximum anaerobic muscle power (alactic) appears to be avoidable by food intake matched to energy expenditure. It may be achieved simply by proper acclimatization, sufficient comfort and availability of palatable food [34]. A longitudinal monitoring of altitude climbers who are repeatedly exposed to hypobaric hypoxia among other stressors could be helpful to understand long-term responses, or adaptations of human body to them. However, to the best knowledge of the authors, there are no scientific evidences of longitudinal, long term, sea level reports on this type of athletes. Thus, the aim of this study is to describe physiological and kinanthropometrical changes of a specific individual (highly trained athlete holder of several records as professional climber) who has been intermittently and repeatedly exposed to extreme altitude during $14 \mathrm{yr}$.

\section{Materials AND Methods}

The study is retrospective, longitudinal and based on a single-case. Variables respond to parameters of exercise physiology and kinanthropometry (see Table 1). The measurements of these parameters were made at sea level and their evolution and correlation were analysed according to the part of the season when they were taken PRE expedition ( $7 \pm 2$ days before departure to expedition), POST ( $9 \pm 5$ days after leave expedition base camp) and OFF (Off expedition, as fitness control of the participant), during 14 years (1996-2010).

\section{Participant}

The participant was a Caucasian male aged 27 at the beginning of the period of study (1996) and aged 41 at the end (2010). Highly trained, especially in endurance since his teen age $(\sim 14)$. A remarkable rock climbing training experience among other disciplines related to outdoor sports such as mountain running, mountain biking, trekking, extreme sports etc. featured the sport background of the participant at that time. When the participant accepted to take part in the study, he already was professional climber with at least 10 years of experience on extreme altitude. Grown up at an altitude below $\sim 250 \mathrm{~m}$, started mountaineering and climbing at moderate altitudes in his childhood along with his brother (first fraternal summit of $8000 \mathrm{~m}$ peak, both with no bottled $\mathrm{O}_{2}$ ). He is the $4^{\text {th }}$ lowlander in mountaineering history that has successfully culminated the 14 highest tops of the World (Table 2) without the use of supplementary $\mathrm{O}_{2}$ and holds several records in mountaineering.

The participant, exercise scientists and medical staff of the High Performance Centre of Fadura-Getxo (Spain) were informed about the experimental processes as well as the studies that were made with him, whom accepted them with a written consent. The study was approved by the ethical committee of the University of the Basque Country according to the Declaration of Helsinki and the Data Protection Law of Spain (LOPD 15/1999).

\section{Experimental procedure}

The blood extraction, physical examination, effort test and the meeting with the physicians and trainer of the athlete were carried out according to the standard protocol of the Sport Performance Centre of Fadura-Getxo, Basque Government (Bilbao, Spain) under laboratory standards.

The protocol was the following:

1. 8:30 am. Blood sampling. Blood samples were taken every day of his visit to the centre during the period of study, on an empty stomach, and obtained from the antecubital vein in the decubital-supine position. Then, the samples were collected and analysed under laboratory standards.

2. 8:45 am. Kinanthropometrical measurement. The subject was measured in this order: First $\mathrm{H}$ on tall meter, barefoot and in standing position. Then, $\mathrm{W}$ on the scale, barefoot and in a standing position.
Kinanthropometry - the application of measurement to the study of human size, shape, proportion, composition, maturation and gross function. Its purpose is to help understand human movement in the context of growth, exercise, performance and nutrition [78].

W - body weight expressed in kilograms.

CHO - carbohydrates.

AMREE - American Medical Research Expedition to Everest, carried out in 1981.

F\% - Body at percentage expressed in $\%$ from Carter and Yuhasz formula [41].

SF - skinfold. The skinfold method for estimating percent body fat relies on the relationship between subcutaneous fat and overall body fatness [81].

Physiology - the study of life itself. It is the study of function of all parts of living organisms [80].

PRE - data collected before expedition $(7 \pm 2$ days before expedition base camp arrival).

POST - data collected after expedition ( $9 \pm 5$ days after leave expedition base camp).

OFF - Data collected during the season as athlete's control test. 
RHR - physiol. Subject's heart rate registered just before the effort test. It has been taken after a quick warm up. Beats per minute. Resting heart rate decreases as a result of endurance training. Expressed in beats per minute [79].

SBSF - subescapula skinfold thickness in millimetres.

TRSF - triceps skinfold thickness in millimetres.

ASF - abdominal skinfold thickness in millimetres.

TSF - thigh skinfold thickness in millimetres.

CSF - calf skinfold thickness in millimetres.

$\sum 6 \mathrm{SF}$ - skinfolds summatory in millimetres.

$\mathbf{H}$ - body height expressed in centimetres.

Himalayism - Alpinist activity featured by reaching mountains above $7000 \mathrm{~m}$ above sea level.

SMHR - physiol. Subject's heart rate at sub-maximum workload. Expressed in beats per minute. Corresponds to $80 \%$ of the maximal theoretical heart rate and its rates are likewise lower during exercise at the same workload, generally by 10 to 20 beats/min or more [79].

SPSF - suprailiac skinfold thickness in millimetres.

ISAK - International Standards for Kinanthropometric Assessment.

GRE - Spanish group of kinanthropometry.

Table 1. Climber's profile.

\begin{tabular}{|c|c|c|c|c|}
\hline \multirow{2}{*}{ Variable (Measurement Unit) } & \multicolumn{4}{|c|}{ Mean $\pm S D$} \\
\hline & Total & Pre & Post & Off \\
\hline \multicolumn{5}{|c|}{ Physiology } \\
\hline RHR (beats $\cdot$ minute $^{-1}$ ) & $78 \pm 8$ & $77 \pm 6$ & $79 \pm 10$ & $77 \pm 7$ \\
\hline SMHR (beats.minute ${ }^{-1}$ ) & $176 \pm 6$ & $177 \pm 5$ & $176 \pm 4$ & $176 \pm 7$ \\
\hline MHR (beats $\cdot$ minute $^{-1}$ ) & $182 \pm 5$ & $182 \pm 4$ & $181 \pm 4$ & $182 \pm 6$ \\
\hline $\mathrm{R}[\mathrm{LA}]\left(\mathrm{mmol} / \mathrm{L}^{-1}\right)$ & $0.8 \pm 0.2$ & $0.8 \pm 0.2$ & $0.8 \pm 0.2$ & $0.8 \pm 0.2$ \\
\hline $\mathrm{M}[\mathrm{LA}]\left(\mathrm{mmol} / \mathrm{L}^{-1}\right)$ & $7.3 \pm 1.7$ & $7.8 \pm 2.1$ & $7.3 \pm 1.9$ & $6.8 \pm 1$ \\
\hline $\mathrm{V}_{2 \max }\left(\mathrm{ml}^{-1} \cdot \mathrm{kg}^{-1} \cdot \mathrm{min}^{-1}\right)$ & $70.8 \pm 4.4$ & $71.5 \pm 3.2$ & $68.9 \pm 4.6$ & $72 \pm 4.8$ \\
\hline \multicolumn{5}{|c|}{ Kinanthropometry } \\
\hline $\mathrm{H}(\mathrm{cm})$ & $187 \pm 0.0$ & $187 \pm 0.0$ & $187 \pm 0.0$ & $187 \pm 0.0$ \\
\hline W (kg) & $72.7 \pm 1.0$ & $72.5 \pm 1.1$ & $72.7 \pm 1$ & $73.0 \pm 1.1$ \\
\hline BMI $\left(\mathrm{kg} \cdot \mathrm{m}^{2}\right)$ & $20.8 \pm 0.3$ & $20.8 \pm 0.3$ & $20.8 \pm 0.2$ & $20.9 \pm 0.3$ \\
\hline SBSF (mm) & $8.0 \pm 0.8$ & $7.4 \pm 0.6$ & $8.0 \pm 0.9$ & $8.5 \pm 0.8$ \\
\hline TSF (mm) & $3.8 \pm 0.2$ & $3.7 \pm 0.2$ & $3.8 \pm 0.2$ & $3.8 \pm 0.2$ \\
\hline SISF (mm) & $4.4 \pm 0.2$ & $4.2 \pm 0.1$ & $4.6 \pm 0.2$ & $4.3 \pm 0.3$ \\
\hline $\mathrm{ABSF}(\mathrm{mm})$ & $5.6 \pm 0.5$ & $5.2 \pm 0.4$ & $6.0 \pm 0.3$ & $5.5 \pm 0.4$ \\
\hline CUAD (mm) & $5.4 \pm 0.6$ & $5.3 \pm 0.2$ & $5.2 \pm 0.2$ & $5.7 \pm 0.9$ \\
\hline $\mathrm{CSF}(\mathrm{mm})$ & $3.8 \pm 0.4$ & $3.8 \pm 0.2$ & $3.8 \pm 0.1$ & $3.9 \pm 0.4$ \\
\hline$\sum 6 \mathrm{SF}(\mathrm{mm})$ & $30.9 \pm 1.8$ & $29.7 \pm 1$ & $31.3 \pm 1.4$ & $31.6 \pm 2.3$ \\
\hline $\mathrm{F} \%(\%)$ & $6.0 \pm 0.3$ & $6.0 \pm 0.2$ & $6.0 \pm 0.3$ & $6.0 \pm 0.3$ \\
\hline
\end{tabular}

RHR - rest heart rate; SMHR - submaximal heart rate; $M H R$ - maximal heart rate; $\mathrm{VO}_{2 \max }$ - maximum oxygen uptake; $\mathrm{R}[\mathrm{LA}]$ - rest blood lactate concentration; $\mathrm{M}[\mathrm{LA}]$ - maximum blood lactate concentration; $\mathrm{H}$ - height; $\mathrm{W}$ - weight; BMI - body mass index; SBSF - subescapular skinfold; TRSF - tricipital skinfold; SISF - suprailiac skinfold; ASF - abdominal skinfold; TSF - thigh skinfold; CSF - calf skinfold; $\Sigma 6 S F$ - skinfold summatory; F\% - fat percentage.

Skin folds were measured with the callipers following the indications of International Standards for Kinanthropometric Assessment (ISAK), approved by the Spanish Group of Kinanthropometry (GRE).

3. 10:00 am. Effort Test. The climber performed a staggered, progressive, intervallic, maximal test of effort (running) on a treadmill following the protocol of Clasingand Siegfried [35]. Constant increases of intensity (every $3 \mathrm{~min}$ ) with rest intervals (20 s) were done during the test. The test began with a speed of $8 \mathrm{~km} / \mathrm{h}$ and $1.5 \%$ grade (stage I) and every $3 \mathrm{~min}, 2 \mathrm{~km} / \mathrm{h}$ is added progressively with $20 \mathrm{sec}$ rest breaks mentioned above until volimic exhaustion. In order to register the athlete's recovery capacity, physiological parameters were registered 1, 2 and 3 min after exhaustion. For the $[\mathrm{LA}]$ analysis, the ear lobe was punctured and peripheral blood taken previously, to test every rest break between stages, at the end of the test and recovery periods (1, 2 and $3 \mathrm{~min}$ ). The $\mathrm{HR}$ and $\mathrm{VO}_{2}$ max were continuously monitored until $3 \mathrm{~min}$ after the test.
4. Supervision of the evolution of the training. Fitness status as well as training progress were analysed exercise scientists and medical and staff.

5. Fitness program schedule. Exercise scientists along with medical staff assessed sport aims and training patterns.

6. Nutritional advising. Medical staff and nutritionists fixed diet, intake needs, hydration rules for training and expeditions.

\section{Instruments and measurements}

The instrumentation used for measurements was the following:

For physiological parameters, the HR (beats $\mathrm{min}^{-1}$ ) was registered beat to beat by Polar Team Advantage Monitor Ltd. (Polar, Kempele Finland) [36]. For the [LA] analysis $\left(\mathrm{mmol} / \mathrm{L}^{-1}\right)$ the blood was taken with a pipette needle (YSI 1500, calibrated with 5 and $15 \mathrm{mmol} / \mathrm{L}^{-1}$ standard solutions) (Sport Yellow Springs Instrument Ltd., 
Table 2. $148,000 \mathrm{~m}$ summits chronology.

\begin{tabular}{cccc}
\hline $\begin{array}{c}\text { Date } \\
\text { (dd-mm-yyy) }\end{array}$ & $\begin{array}{c}\text { Age } \\
(\mathbf{y r})\end{array}$ & Summited Peak & $\begin{array}{c}\text { Altitude } \\
(\mathbf{m})\end{array}$ \\
\hline $30-09-1991$ & 22 & Makalu & 8,465 \\
\hline $25-09-1992$ & 23 & Everest & 8,848 \\
\hline $26-05-1994$ & 25 & K2 (Chogori) & 8,611 \\
\hline $11-09-1995$ & 26 & Cho Oyu & 8,201 \\
\hline $27-09-1995$ & 26 & Lhotse & 8,516 \\
\hline $06-05-1996$ & 27 & Kanchenjunga & 8,586 \\
\hline $11-10-1996$ & Shisha Pangma & 8,046 \\
\hline $13-07-1997$ & 27 & Broad Peak & 8,047 \\
\hline $22-05-1998$ & 28 & Dhaulagiri & 8,167 \\
\hline $29-07-1999$ & 29 & Nanga Parbat & 8,125 \\
\hline $25-04-2000$ & 30 & Manaslu & 8,163 \\
\hline $28-07-2000$ & 31 & Gasherbrum II & 8,035 \\
\hline $08-07-2001$ & 31 & Gasherbrum I & 8,068 \\
\hline $16-05-2002$ & 32 & Annapurna & 8,091 \\
\hline
\end{tabular}

dd-mm-yyyy - day-month-year; yr - year; m - meters.

OH, USA) [37]. The measurements of composition and volumes of the breathed air were taken with equipment Jaeger Oxycon Pro Ltd. (Würzberg, Germany) [38] and $\mathrm{VO}_{\text {max }}$ expressed in $\mathrm{ml} \cdot \mathrm{kg}^{-1} \cdot \mathrm{min}^{-1}$.

In kinanthropometry measurements, the study followed the International Standards for Anthropometric Assessment (ISAK), approved by the Spanish Group of Kinanthropometry (GRE) [39]. The H (cm) was taken by a tallimeter model SECA Ltd. (Germany), with a precision of $2 \mathrm{~mm}$ and a range 130 to $210 \mathrm{~cm}$. The $\mathrm{W}(\mathrm{kg})$ was recorded by a scale model SECA Ltd. (Germany), with a precision of $0.2 \mathrm{~kg}$ and a range $2 \mathrm{~kg}$ to $130 \mathrm{~kg}$. $6 \mathrm{SF}$, (subescapula (SBSF), tricipital (TRSF), suprailiac (SISF), abdominal (ASF), thigh (TSF), calf (CSF), were measured with calipers (Holtain Ltd., Crymych, UK) with a precision of $0.2 \mathrm{~mm}$ [40]. The sum of them was also registered $\left(\sum 6 \mathrm{SF}\right)$. The fat percentage (F\%) was calculated with Carter and Yuhasz equation [41]:

Carter and Yuhasz Equation: $=(0.1051 \times[\mathrm{SBSF}+$ $\mathrm{TRSF}+\mathrm{SISF}+\mathrm{ASF}+\mathrm{TSF}+\mathrm{CSF}]+2.585$

\section{Statistical analysis}

Descriptive data are expressed as means \pm standard deviation (SD). To analyse changes in variables during the period of study ANOVA (repeated measures) test was used, for elite single-case athletes [42]. Bonferroni Post Hoc Test was used for group comparisons (season parts; PRE, POST and OFF). The correlation between the age of the participant and his kinanthropometry and physiology parameters was evaluated by means of a bivariate linear correlation (Pearson coefficient). Significant levels were set at $(\mathrm{P}<0.05)^{*}$ for both statistical analyses. SPSS statistical package version 17.0 (SPSS, Chicago, USA) was used.

\section{Results}

HR. Differences in RHR, SMHR and MHR were not observed during the period of study regarding to the season part when they were performed. However, the following correlations were found: MHR vs. M[LA]* ( $181 \pm 6 \mathrm{bpm}$ vs. $7.3 \pm 1.7 \mathrm{mmol} / \mathrm{L}^{-1}$ ) and MHR vs. $\mathrm{VO}_{2 \max } *\left(182 \pm 5 \mathrm{bpm} v s .70 .8 \pm 4.4 \mathrm{ml} \cdot \mathrm{kg}^{-1} \cdot \mathrm{min}^{-1}\right), \mathrm{SMHR}$ vs. Age* (176 6 bpm vs. $34 \pm 4 \mathrm{yr})$ and MHR vs. Age* ( $182 \pm 5$ bpm vs. $34 \pm 4$ yr). $\mathrm{VO}_{2 \max }$ did not present differences during the analysed period related to the season parts. A significant correlation with the MHR is described above. [LA] differences in its evolution have not been found, but it is correlated significantly with MHR as previously mentioned. Kinanthropometry. Significant differences in SF were observed in SISF and ASF after expeditions; SISF [PRE $(7.4 \pm 0.6 \mathrm{~mm}) / \mathrm{OFF}$ $(8.5 \pm 0.8 \mathrm{~mm})$ vs. POST* $(8.0 \pm 0.9 \mathrm{~mm})]$ and ASF [PRE $(5.2 \pm 0.4 \mathrm{~mm}) / \mathrm{OFF}(5.5 \pm 0.4 \mathrm{~mm})$ vs. POST* $(6.0 \pm 0.3$ $\mathrm{mm})]$ whereas $\sum 6 \mathrm{SF}$ showed differences between PRE and OFF [PRE $(29.7 \pm 1 \mathrm{~mm}$ vs. OFF* $(31.6 \pm 2.3 \mathrm{~mm})$. Negative correlations were observed at $\mathrm{W}(72.7 \pm 1 \mathrm{~kg})$ vs. Age (34 $\pm 4 \mathrm{yr})$; SBSF $(8.0 \pm 0.8 \mathrm{~mm})$ vs. Age $(34 \pm 4$ 


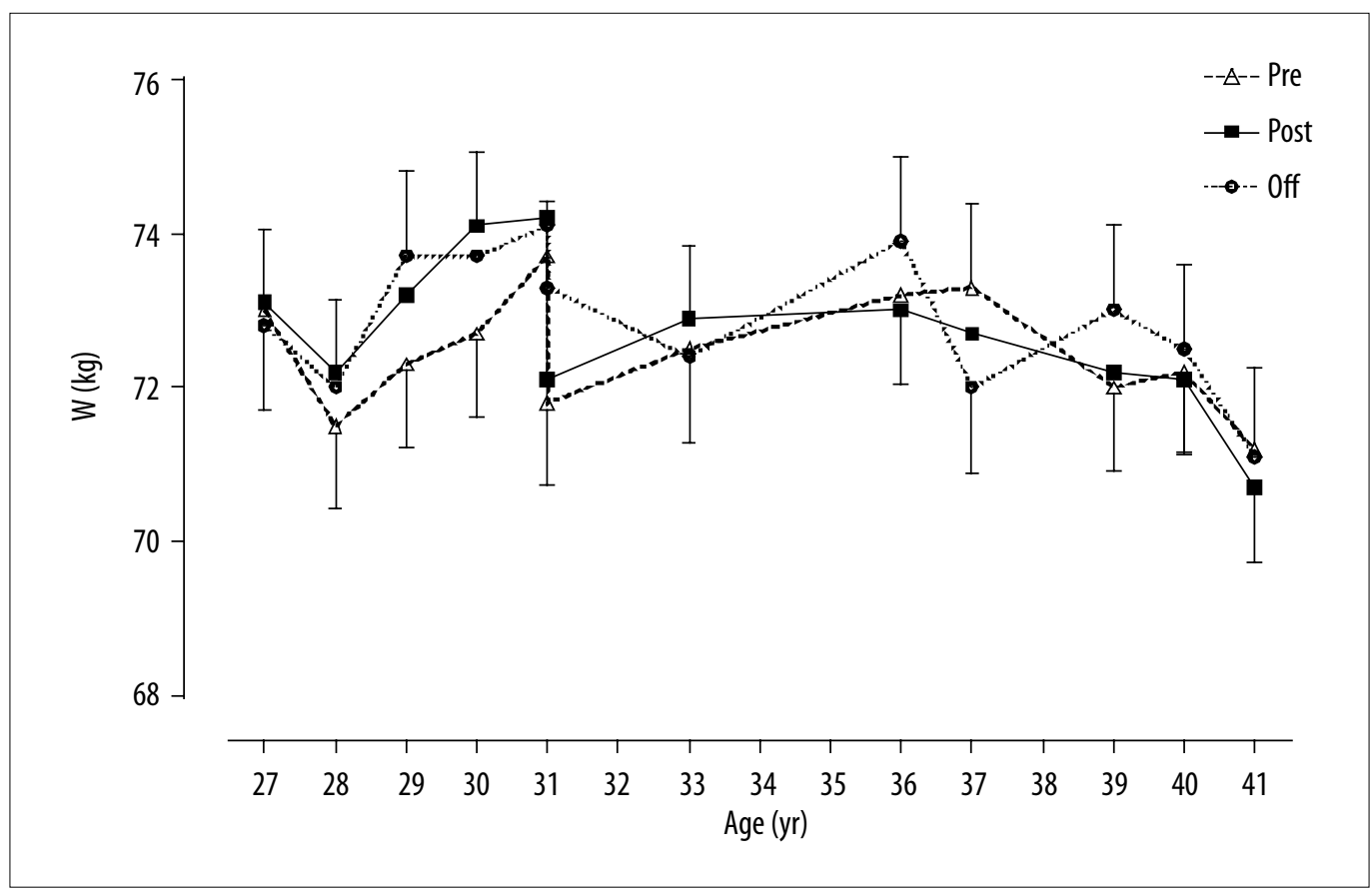

Figure 1. Evolution of weight.

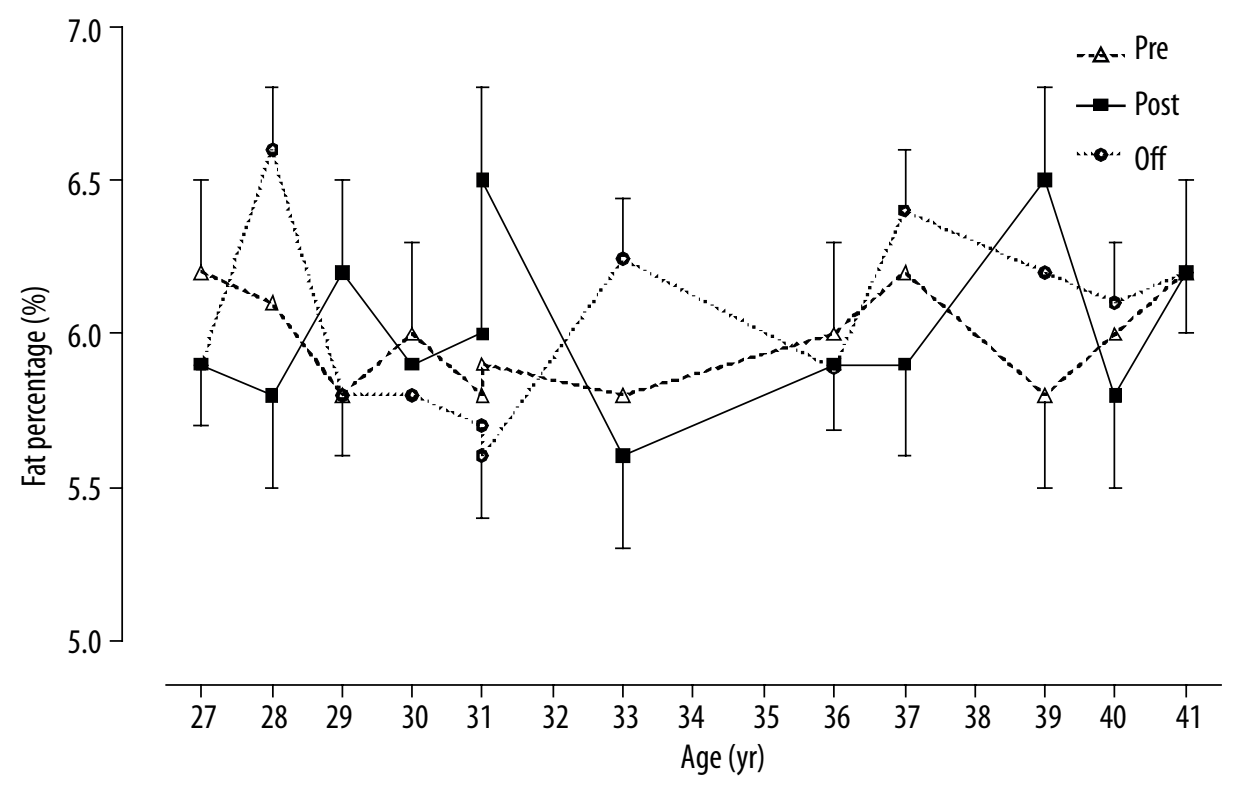

Figure 2. Evolution of fat percentage.

yr); $\sum 6 \mathrm{SF}(30.9 \pm 1.8 \mathrm{~mm})$ Age $(34 \pm 4 \mathrm{yr}) ; \mathrm{W}(72.7 \pm 1$ $\mathrm{kg})$ vs. $\sum 6 \mathrm{SF}(30.9 \pm 1.8 \mathrm{~mm}) ; \mathrm{W}(72.7 \pm 1 \mathrm{~kg})$ vs. $\% \mathrm{~F}$ $(6 \pm 0.3 \%)]$.

\section{Discussion}

The purpose of this study is to describe the changes occurred through the years in a top level climber who is repeatedly exposed to extreme altitudes and analyse whether this exposures are related to changes at kinanthropometrical and/or physiological level

HR. Extreme altitude climbing has been traditionally studied by scientists and physicians in expeditions [43-47]. The rise in RHR and during exercise starts even at moderate altitudes [48] and returns to sea level values hours after descent. In our follow up study through the time we did not observe significant differences between season parts (PRE vs. POST vs. OFF) in HR. These data 


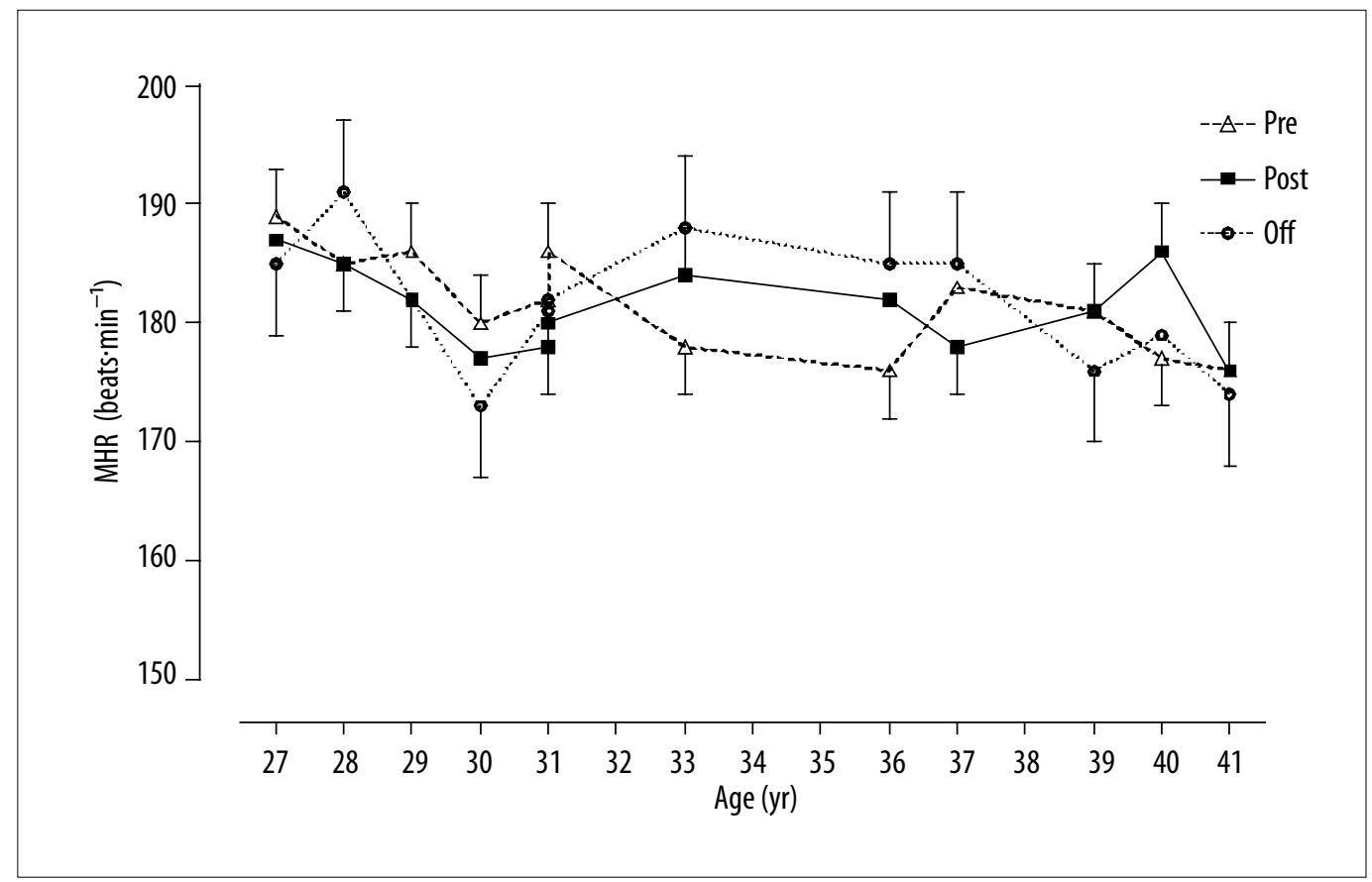

Figure 3. Evolution of maximal heart rate.

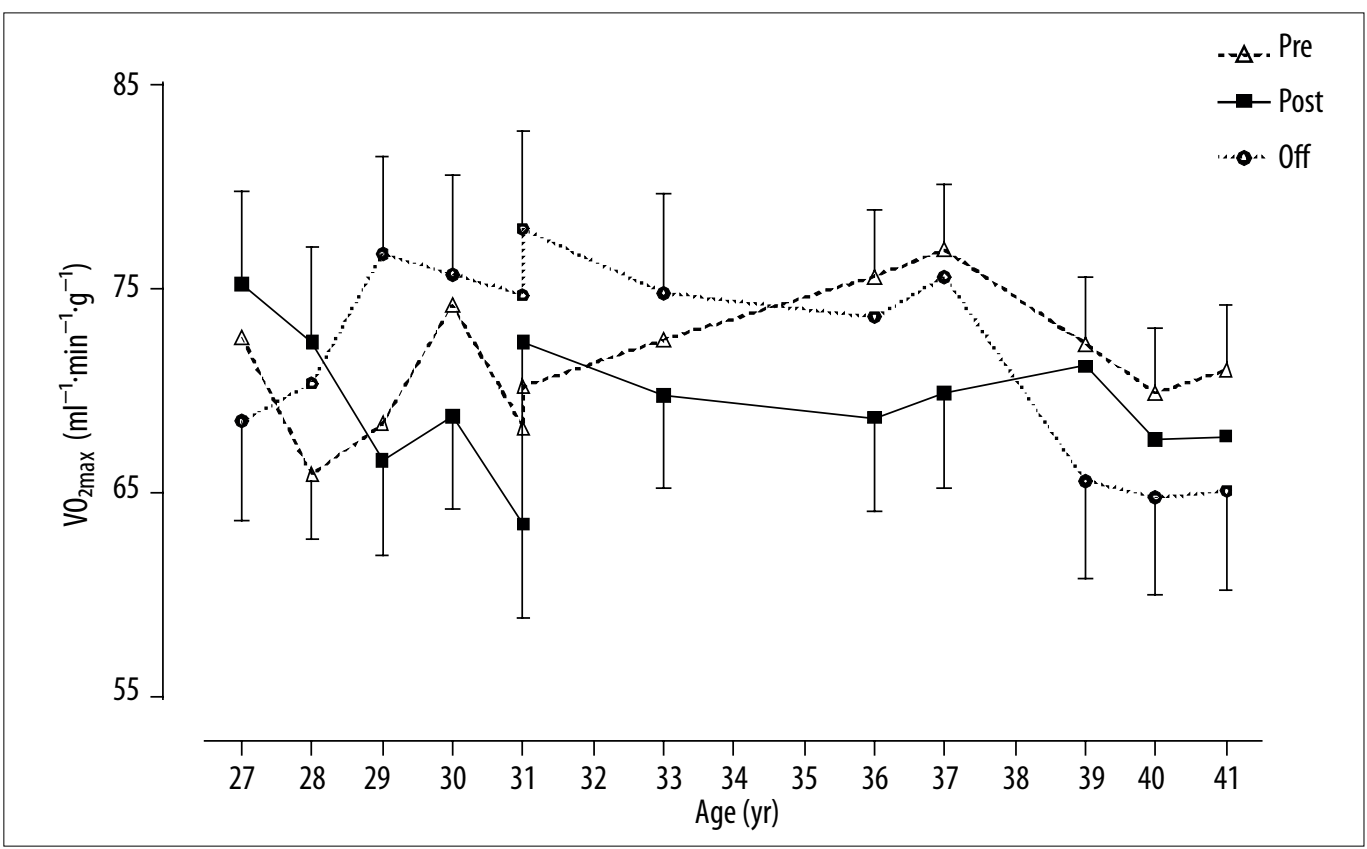

Figure 4. Evolution of maximal oxygen consumption.

agree with those provided by the EEIII, where significant differences in this sense did not exist at maximal workloads when the analysed subjects returned to sea level. According to Malconian's work, most changes reverted back to normal within 12 hours of returning to sea level in electrocardiogram at rest and exercise during a simulated ascent of Mt. Everest (Operation Everest II) (49). Significant correlations were observed between MHR vs. M[LA $]^{*}$. These results agree with data published by Tanaka et al. [50]; Bangsbo et al. [51] and Saltin et al.
[52]. In these studies, highly trained athletes presented a relationship between these two parameters at maximal exercise. The decline in SMHR $(\mathrm{P}<0.0001)$ and MHR $(\mathrm{P}<0.001)$ through the time (age 27 to 41 years) can be related to aging process of the participant. This two variables showed a significant correlation towards the age. Is well known that aging decreases maximal heart rate and is linear for a given individual [53]. This aging effect on cardiovascular parameters has been previously reported in other follow up studies with highly trained 


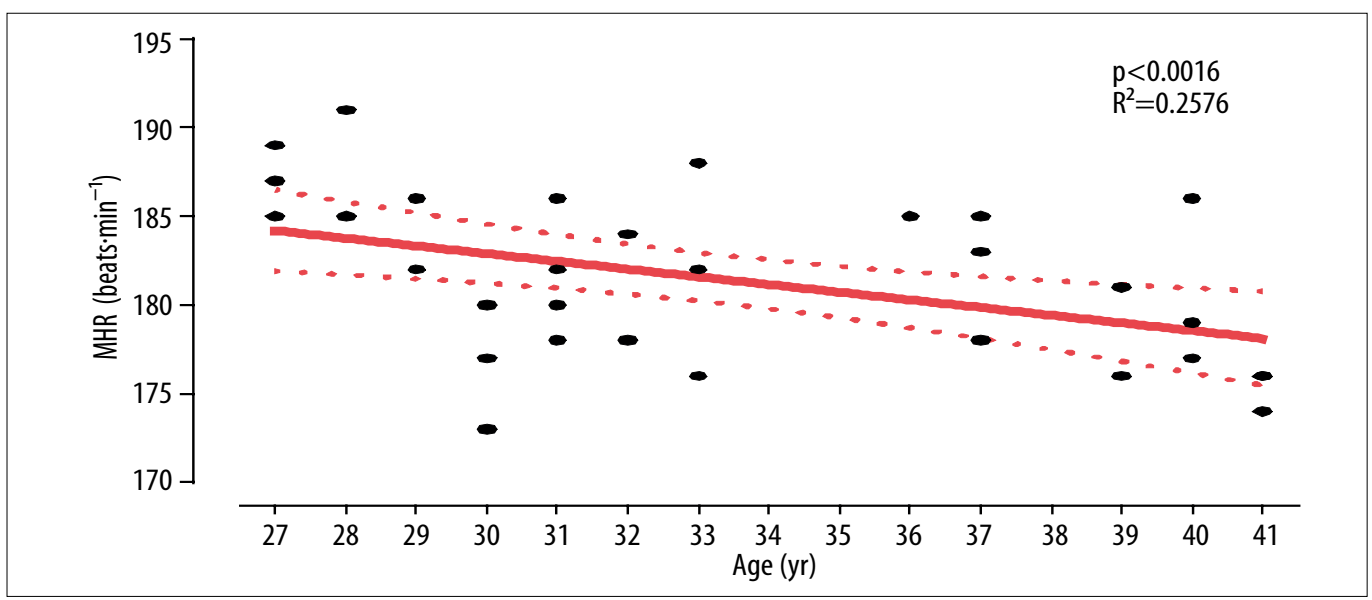

Figure 5. Maximal heart rate decline.

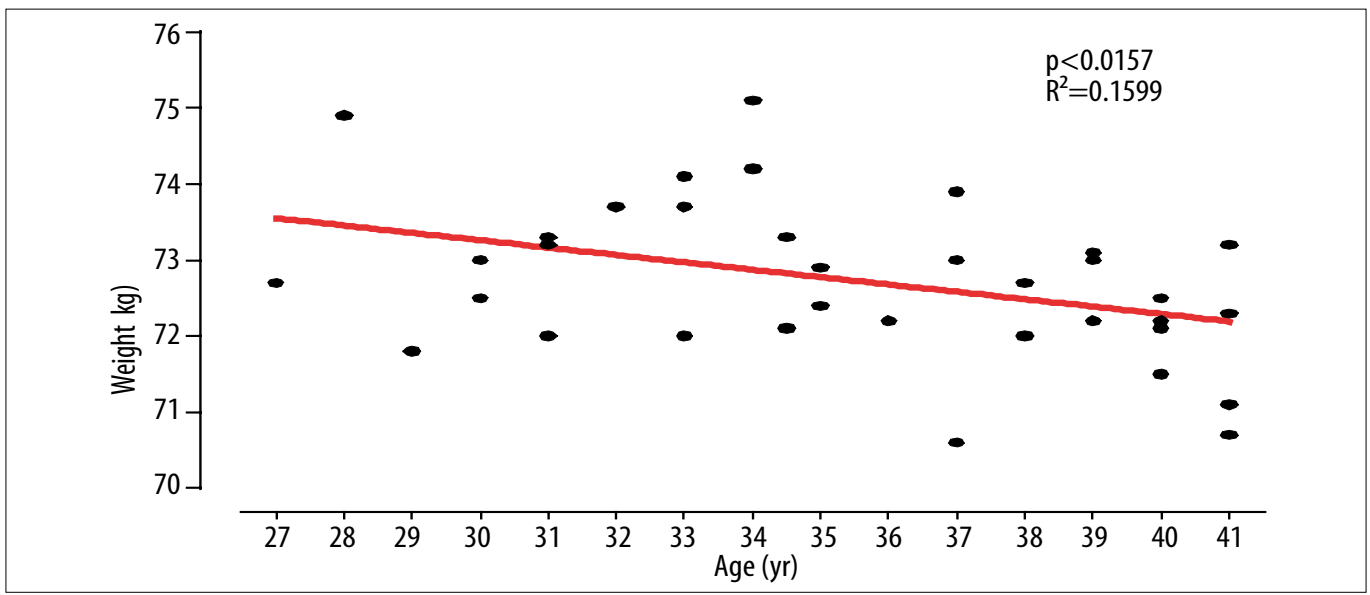

Figure 6. Correlation between weight and aging.

athletes [54,55]. Quinn et al. tested different age groups of competitive runners. In the same age group of tested athletes, ("Y group", $n=18$ ages from 18 to 39) the decline in strength and power were significantly related to running velocity, indicating that age-related declines in running performance are associated with declines in maximal and submaximal cardiorespiratory variables [55]. Therefore, it can be concluded that the decline in the physiological capacity of humans is an inevitable consequence of the biological aging process [56].

$\mathrm{VO}_{2 \max }$ is one of the most used parameters in sport training theory to determine the intensity of exercise in low and high altitudes [57-60]. At the altitude of Mt Everest, maximal oxygen uptake is reduced to $20-25 \%$ of its sea level [6]. The $\mathrm{VO}_{2 \max }$ of the participant during the studied period was $70.5 \pm 4.7 \mathrm{ml} \cdot \mathrm{kg}^{-1} \cdot \mathrm{min}^{-1}$, considerably higher than the data provided by Oelz [61] where successful non bottled $\mathrm{O}_{2}$ users showed values around $60 \pm 6 \mathrm{ml} \cdot \mathrm{kg}^{-1} \cdot \mathrm{min}^{-1}$. On the other hand, changes were not observed in relation to expeditions. This data is consistent with Cerretelli's work. He measured $\mathrm{VO}_{2 \max }$ in a group of subjects at sea level shortly before exposition to an altitude of $5.350 \mathrm{~m}$ for $10-12$ weeks, and again at sea level about 4 weeks after their return from altitude. Although there was an approximately 1 1\% (PRE vs. POST) increase in haemoglobin concentration, this was not accompanied by a statistically significant rise in $\mathrm{VO}_{2 \mathrm{ma}}$ [62]. Perhaps the reduction of muscle mass fibre size at very high altitude is the explanation for the failure to see an increase in $\mathrm{VO}_{2 \max }$ after exposure to these extreme environments $[63,64]$. Failure to recover $\mathrm{VO}_{2 \max }$ after acclimatization despite normalization of arterial $\mathrm{O}_{2}$ concentration is explained by two circulatory effects of altitude: 1) failure of cardiac output to normalize and 2 ) preferential redistribution of cardiac output to nonexercising tissues [65].

The level of [LA] is known to be very low in acclimatized subjects at high altitude even during maximal work [66] although other recent studies have shown values in the opposite direction [14,67]. This paradox remains still unclear $[17,68]$. We have not found in existing scientific bibliography works of the evolution of this parameter after extreme altitude expeditions. Oelz et al. presented data of some legendary elite climbers $(n=6)$ 
made at sea level, showing M[LA] values of $11.9 \pm 3.3$ $\mathrm{mmol} / \mathrm{L}^{-1}$ after performing 2 treadmill tests. The subject analysed in our study showed M[LA] values of 7.1 $\mathrm{mmol} / \mathrm{L}^{-1}$ after treadmill tests during his career. We have not found a significant differences in $\mathrm{R}[\mathrm{LA}]$ and $\mathrm{M}[\mathrm{LA}]$ related to when the test was performed. Both data (as well as $\mathrm{VO}_{2 \max }$ values) show the high fitness level of the participant in the present study. On the other hand Robach et al. [25], in EEIII, observed significant changes in M[LA] for the control group [69].

Kinanthropometry at extreme altitude has traditionally been focused in body changes produced during expeditions, analysing the data collected immediately before and immediately after $[27,33,34,70-73]$. In the present study, SISF, ABSF and the $\sum 6 \mathrm{SF}$ presented changes after expedition [SISF PRE $(7.4 \pm 0.6 \mathrm{~mm}) / \mathrm{OFF}(8.5 \pm 0.8 \mathrm{~mm})$ vs. POST* $(8.0 \pm 0.9 \mathrm{~mm}), \operatorname{ABSF} \operatorname{PRE}(5.2 \pm 0.4 \mathrm{~mm}) /$ OFF $(5.5 \pm 0.4 \mathrm{~mm}) v s$. POST* $(6 \pm 0.3 \mathrm{~mm})$ and $\sum 6 \mathrm{SF}$ PRE $(29.7 \pm 1.0 \mathrm{~mm}) / \mathrm{OFF}(31.6 \pm 2.3 \mathrm{~mm})$ vs. POST* $(31.3 \pm 1.4 \mathrm{~mm})$. These data contrast with majority of the studies that confirm the $\mathrm{W}$ loss, mentioned above with the exception of Kayser et al. [34] who demonstrated that an altitude of $5050 \mathrm{~m}$, loss of body mass from fat and muscle tissue, and hence impairment of maximum anaerobic muscle power (alactic) appears to be avoidable by food intake matched to energy expenditure. The latter may be achieved simply by proper acclimatization, sufficient comfort and availability of palatable food. However, it's unknown the physical fitness level of participants in that study, whereas the participant of the present study showed a highly trained athlete profile. Aging appears to have an impact in body composition, especially process in sedentary population increasing body fat and body mass. However, muscle lean mass can be preserved and thus, athletic performance at some aging stages [74]. Our data indicate that $\mathrm{W}(72.7 \pm \mathrm{l} \mathrm{kg})$, BMI $\left(20.8 \pm 0.3 \mathrm{~kg} . \mathrm{m}^{2}\right)$ and $\sum 6 \mathrm{SF}$ $(30.9 \pm 1.8 \mathrm{~mm})$ slightly decrease especially in the last part of the period of study (36 to $41 \mathrm{yr}$ ). This fat/weight loss can be due to different causes. The high fitness level and the development of the new training strategies based in a long endurance programs promoting lipolytic pathways might be one of the main causes. However, as some authors reported in their studies, top-level athletes might present extraordinary rare values due to individual variability and other several factors [75].

\section{Conclusions}

This report has identified the physiological and kinanthropometrical features of an elite climber from ages 27 to 41 who has become the 4th of alpinism history reaching all highest peaks of the earth "by fair means" (without supplementary $\mathrm{O}_{2}$ ) [76]. It might be concluded that as a result of sport training preparation and his broad climbing career, analysed parameters showed a stable pattern through the years with slightly variations. Exposure to extreme altitude conditions does not seem to modify athlete's either kinanthropometrical or physiological profile. Nevertheless the aging process appears to have a certain effect at physiological level with a decline at cardiovascular capacity.

\section{Limitations of the study}

Given the complexity of the expeditions, participant performed tests as close as it was possible to departure/arrival dates and when logistics permitted it. On the other hand, single case studies have to deal with several factors such as the little interest in generalizing to a population.

\section{Acknowledgements}

The authors of the article appreciate the collaboration of the Technical Improvement and Sport Performance Centre Staff of Fadura-Getxo (Bilbao) and the climber who participated in the study.

\section{References:}

1. Gallagher SA, Hackett PH: High-altitude illness. EmergMedClinNorth Am, 2004; 22(2): 329-55, viii

2. Cymerman A, Reeves JT, Sutton JR et al: Operation Everest II: maximal oxygen uptake at extreme altitude. JApplPhysiol, 1989; 66(5): 2446-53

3. West JB: Recent advances in human physiology at extreme altitude. Adv Exp Med Biol, 1999; 474: 287-96

4. Singh I, Khanna PK, Lal M et al: High-Altitude Pulmonary Hypertension. Lancet, 1965; 1(7404): 146-50

5. Schoene RB: High in the cold, thin air: risks and benefits. J Am Coll Health Assoc, 1980; 29(3): 143-44

6. West JB: Limiting factors for exercise at extreme altitudes. Clin Physiol, 1990; 10(3): 265-72
7. Allemann Y, Saner H, Meier B: [High altitude stay and air travel in coronary heart disease]. Schweiz Med Wochenschr, 1998; 128(17): 671-78

8. Martin DS, Levett DZ, Grocott MP, Montgomery HE: Variation in human performance in the hypoxic mountain environment. Exp Physiol, 2010; 95(3): 463-70

9. Dejours P, Kelloggrh, Pace N: Regulation of respiration and heart rate response in exercise during altitude acclimatization. J Appl Physiol, 1963; 18: $10-18$

10. Hirata K, Ban T, Jinnouchi Y, Kubo S: Echocardiographic assessment of left ventricular function and wall motion at high altitude in normal subjects. Am J Cardiol, 1991; 68(17): 1692-97

11. Lundby C, van HG: Peak heart rates at extreme altitudes. High Alt Med Biol, 200 I; 2(1): 41-45
12. Pugh LG: Man at high altitude: studies carried out in the Himalaya. Sci Basis Med Annu Rev, 1964: 32-54

13. Sutton JR, Reeves JT, Wagner PD et al: Operation Everest II: oxygen transport during exercise at extreme simulated altitude. J Appl Physiol, 1988; 64(4): 1309-21

14. van Hall G, Lundby C, Araoz M et al: The lactate paradox revisited in lowlanders during acclimatization to $4100 \mathrm{~m}$ and in high-altitude natives. J Physiol, 2009; 587(Pt 5): 1117-29

15. Richalet JP: Commentaries on viewpoint: evidence that reduced skeletal muscle recruitment explains the lactate paradox during exercise at high altitude. J Appl Physiol, 2009; 106(2): 743-44 
16. Noakes TD: Evidence that reduced skeletal muscle recruitment explains the lactate paradox during exercise at high altitude. J Appl Physiol, 2009; 106(2): 737-38

17. Noakes TD: Last word on viewpoint: evidence that reduced skeletal muscle recruitment explains the lactate paradox during exercise at high altitude. J Appl Physiol, 2009; 106(2): 745

18. West JB: Point: the lactate paradox does/does not occur during exercise at high altitude. J Appl Physiol, 2007; 102(6): 2398-99

19. Wagner PD, Lundby C: The lactate paradox: does acclimatization to high altitude affect blood lactate during exercise? Med Sci Sports Exerc, 2007; 39(5): 749-55

20. Brooks GA, Wolfel EE, Butterfield GE et al: Poor relationship between arterial [lactate] and leg net release during exercise at $4,300 \mathrm{~m}$ altitude. Am J Physiol, 1998; 275(4 Pt 2): Rl 192-201

21. Noakes TD: Evidence that reduced skeletal muscle recruitment explains the lactate paradox during exercise at high altitude. J Appl Physiol, 2009; 106(2): 737-38

22. Savard GK, Areskog NH, Saltin B: Cardiovascular response to exercise in humans following acclimatization to extreme altitude. Acta Physiol Scand, 1995; 154(4): 499-509

23. Pak GD, Seluianov VN, Pivtsov VT, Maevskii VI: [The functional prognosis of physical working ability under conditions of extreme high altitude]. Ross Fiziol Zh Im I M Sechenova, 2011; 97(3): 330-35

24. Cerretelli P, Whipp BJ: Exercise bioenergetics and gas exchange: proceedings of the International Symposium on Exercise Bioenergetics and Gas Exchange, held in Milan, Italy, July 7-9, 1980, a satellite of the XXVIII International Congress of Physiological Sciences. Amsterdam; New York, New York, N.Y.: Elsevier/North-Holland Biomedical Press; sole distributors for the USA and Canada, Elsevier North Holland; 1980

25. Robach P, Dechaux M, Jarrot S et al: Operation Everest III: role of plasma volume expansion on $\mathrm{VO}(2)(\max )$ during prolonged high-altitude exposure. J Appl Physiol, 2000; 89(1): 29-37

26. Takahashi H, Asano K, Kikuchi K: [Control of ventilation and aerobic work capacity in elite climbers]. Ann Physiol Anthropol, 1990; 9(1): 31-39

27. Sergi G, Imoscopi A, Sarti S et al: Changes in total body and limb composition and muscle strength after a 6-8 weeks sojourn at extreme altitude $(5000-$ $8000 \mathrm{~m})$. J Sports Med Phys Fitness, 2010; 50(4): 450-55

28. Hamad N, Travis SP: Weight loss at high altitude: pathophysiology and practical implications. Eur J Gastroenterol Hepatol, 2006; 18(1): 5-10

29. Kormanovski A, Harasymowicz J: Survival adaptation in everest: Metabolic response during acclimatization in lowlander and sherpa climbers. Arch Budo, 2010; 6(2): 83-89

30. Pugh LG: Physiological and medical aspects of the Himalayan scientific and mountaineering expedition, 1960-61. Br Med J, 1962; 2(5305): 621-27

31. Milledge JS: Arterial oxygen desaturation and intestinal absorption of xylose. Br Med J, 1972; 3(5826): 557-58

32. Boyer SJ, Blume FD: Weight loss and changes in body composition at high altitude. J Appl Physiol, 1984; 57(5): 1580-85

33. Kayser B, Acheson K, Decombaz J et al: Protein absorption and energy digestibility at high altitude. J Appl Physiol, 1992; 73(6): 2425-31

34. Kayser B, Narici M, Milesi S et al: Body composition and maximum alactic anaerobic performance during a one month stay at high altitude. Int J Sports Med, 1993; 14(5): 244-47

35. Clasing D, Al-Bazaz S: Sportärztliche Untersuchung und Beratung: Spitta-Verl, 2002
36. Dahlstrom N, Nahlinder S: A comparison of two recorders for obtaining in-flight heart rate data. Appl Psychophysiol Biofeedback, 2006; 31(3): 273-79

37. Buckley JD, Bourdon PC, Woolford SM: Effect of measuring blood lactate concentrations using different automated lactate analysers on blood lactate transition thresholds. J Sci Med Sport, 2003; 6(4): 408-2 I

38. Foss O, Hallen J: Validity and stability of a computerized metabolic system with mixing chamber Int J Sports Med, 2005; 26(7): 569-75

39. Hume P, Marfell-Jones M: The importance of accurate site location for skinfold measurement. J Sports Sci, 2008; 26(12): 1333-40

40. Rehs HJ, Berndt I, Rutenfranz J, Burmeister W: [Determination of lean body mass by skin fold measurements (author's transl)]. Z Kinderheilkd, 1975; 120(2): 121-33

41. Carter JEL: Physical structure of Olympic athletes: Kinanthropometry of Olympic athletes: Karger, 1984

42. Kinugasa T, Cerin E, Hooper S: Single-subject research designs and data analyses for assessing elite athletes' conditioning. Sports Med, 2004; 34(15): 1035-50

43. Aigner A, Berghold F, Muss N: [Investigations on the cardiovascular system at altitudes up to a height of 7,800 meters (author's transl)]. Z Kardiol. 1980; 69(9): 604-10

44. West JB, Boyer SJ, Graber DJ et al: Maximal exercise at extreme altitudes on Mount Everest. J Appl Physiol, 1983; 55(3): 688-98

45. Wu T: [Changes in cardiac function at rest and during exercise in mountaineers at an extreme altitude]. Zhonghua Yi Xue Za Zhi, 1990; 70(2): 72-76

46. Lundby C, van Hall G: Peak heart rates at extreme altitudes. High Alt Med Biol, 2001; 2(1): 41-45

47. Windsor JS, Rodway GW, Montgomery HE: A review of electrocardiography in the high altitude environment. High Alt Med Biol, 2010; 11 (1): 51-60

48. Milledge JS, Ward MP, Williams ES, Clarke CR: Cardiorespiratory response to exercise in men repeatedly exposed to extreme altitude. J Appl Physiol, 1983; 55(5): 1379-85

49. Malconian M, Rock P, Hultgren $\mathrm{H}$ et al: The electrocardiogram at rest and exercise during a simulated ascent of Mt. Everest (Operation Everest II). Am J Cardiol. 1990; 65(22): 1475-80

50. Tanaka K: Lactate-related factors as a critical determinant of endurance. Ann Physiol Anthropol, 1990; 9(2): 191-202

51. Bangsbo J, Graham T, Johansen L, Saltin B: Muscle lactate metabolism in recovery from intense exhaustive exercise: impact of light exercise. J Appl Physiol, 1994; 77(4): 1890-95

52. Saltin B, Larsen H, Terrados N et al: Aerobic exercise capacity at sea level and at altitude in Kenyan boys, junior and senior runners compared with Scandinavian runners. Scand J Med Sci Sports, 1995; 5(4): 209-21

53. Charansonney OL: Physical activity and aging: a life-long story. Discov Med, 201 1; 12(64): 177-85

54. Trappe SW, Costill DL, Vukovich MD et al: Aging among elite distance runners: a 22 -yr longitudinal study. J Appl Physiol, 1996; 80(1): 285-90

55. Quinn TJ, Manley MJ, Aziz J et al: Aging and factors related to running economy. J Strength Cond Res, 2011; 25(11): 2971-79

56. Rogers MA, Hagberg JM, Martin WH III et al: Decline in $\mathrm{VO}_{2 \max }$ with aging in master athletes and sedentary men. J Appl Physiol, 1990; 68(5): 2195-99

57. Terrados N, Mizuno M, Andersen H: Reduction in maximal oxygen uptake at low altitudes; role of training status and lung function. Clin Physiol, 1985; 5(Suppl.3): 75-79
58. Andersen P, Saltin B: Maximal perfusion of skeletal muscle in man. J Physiol, 1985; 366: 233-49

59. Bangsbo J, Gollnick PD, Graham TE et al: Anaerobic energy production and $\mathrm{O} 2$ deficit-debt relationship during exhaustive exercise in humans. J Physiol, 1990; 422: 539-59

60. Stirling JR, Zakynthinaki MS, Saltin B: A model of oxygen uptake kinetics in response to exercise: including a means of calculating oxygen demand/deficit/debt. Bull Math Biol, 2005; 67(5): 989-1015

61. Oelz O, Howald H, Di Prampero PE et al: Physiological profile of world-class high-altitude climbers. J Appl Physiol, 1986; 60(5): 1734-42

62. Cerretelli P: Limiting factors to oxygen transport on Mount Everest. J Appl Physiol, 1976; 40(5): 658-67

63. Howald H, Hoppeler H: Performing at extreme altitude: muscle cellular and subcellular adaptations. Eur J Appl Physiol, 2003; 90(3-4): 360-64

64. West JB, Schoene RB, Milledge JS: High altitude medicine and physiology. $4^{\text {th }}$ ed ed. London: Hodder Arnold, 2007

65. Calbet JA, Boushel R, Radegran G et al: Determinants of maximal oxygen uptake in severe acute hypoxia. Am J Physiol RegulIntegr Comp Physiol, 2003; 284(2): R291-303

66. Hochachka PW, Beatty CL, Burelle Y et al: The lactate paradox in human high-altitude physiological performance. News Physiol Sci, 2002; 17: 122-26

67. Wagner PD: Origin of the lactate paradox: muscles or brain? J Appl Physiol, 2009; 106(2): 740-41

68. West JB: Point: the lactate paradox does/does not occur during exercise at high altitude. J Appl Physiol, 2007; 102(6): 2398-99

69. Robison JI, Rogers MA, Carlson JJ et al: Effects of a 6-month incentive-based exercise program on adherence and work capacity. Med Sci Sports Exerc, 1992; 24(1): 85-93

70. Boyer SJ, Blume FD: Weight loss and changes in body composition at high altitude. J Appl Physiol, 1984; 57(5): 1580-85

71. Fulco CS, Cymerman A, Pimental NA et al: Anthropometric changes at high altitude. Aviat Space Environ Med, 1985; 56(3): 220-24

72. Fusch C, Gfrorer W, Koch C et al: Water turnover and body composition during long-term exposure to high altitude $(4,900-7,600 \mathrm{~m})$. J Appl Physiol, 1996; 80(4): $1118-25$

73. Hamad N, Travis SP: Weight loss at high altitude: pathophysiology and practical implications. Eur J Gastroenterol Hepatol, 2006; 18(1): 5-10

74. Wroblewski AP, Amati F, Smiley MA et al: Chronic exercise preserves lean muscle mass in masters athletes. Phys Sportsmed, 201 1; 39(3): 172-78

75. Sands WA: Measurement issues with elite athletes. Sports Technology, 2008; 1(2-3): 101-4

76. Messner R, Bittebierre M: Everest sans oxygène. París: Arthaud, 1979

77. Åstrand PO: Textbook of work physiology: physiological bases of exercise. Human Kinetics, 2003

78. Carter JEL: Physical structure of Olympic athletes: Kinanthropometry of Olympic athletes. Karger, 1984

79. Wilmore JH, Costill DL, Kenney WL: Physiology of sport and exercise: Human Kinetics, 2008

80. Guyton AC: Physiology of the human body. Saunders, 1979

81. Brown SP, Miller WC, Eason JM: Exercise Physiology: Basis of Human Movement in Health and Disease. Lippincott Williams \& Wilkins, 2006

82. Haywood K, Getchell N: Life span motor development. Human Kinetics, 2009 